\title{
Effects Of Nutrition Education And Counseling Intervention On Maternal Weight And Obstetric Outcomes Among Pregnant Women Of Gedeo Zone, SNNPR, Ethiopia, 2019, Cluster Randomized Control Trial
}

Gizaw Sisay ( $\sim$ gizsisay@gmail.com )

Dilla University

Adane Tesfaye

Dilla University

Research article

Keywords: Nutrition education, counseling, low birth weight, preterm, Gedeo Zone

Posted Date: September 21st, 2021

DOl: https://doi.org/10.21203/rs.3.rs-129007/v1

License: (c) (i) This work is licensed under a Creative Commons Attribution 4.0 International License.

Read Full License 


\section{Abstract}

\section{Background}

A good approach to improve maternal diet during pregnancy is nutrition education and counseling. However, due to the scarcity of intervention trials, especially in Ethiopia, the effect of nutrition education and counseling intervention on pregnancy outcomes is not well studied.

\section{Objective}

To assess the effect of nutrition education and counseling on maternal weight and the outcomes of pregnancy among pregnant women in public health care institutions of Gedeo Zone, Southern, Ethiopia.

\section{Methods}

A cluster randomized control trial study design was undertaken. Simple random sampling followed by cluster sampling was used to reach eligible study participants. A total sample of 235 (115 intervention vs. 120 control group) pregnant women who followed antenatal care service in public health facilities of Gedeo Zone were included in the study. Independent t-test was used to analyze the group difference for continuous variable and chi-square test for categorical variables. The post intervention values between two groups were compared using ANCOVA by adjusting to the baseline variables.

\section{Result}

After nutrition education and counseling, pregnant women in the control group had less weight gain than in the intervention $(65.03 \mathrm{~kg}$ vs. $56.69 \mathrm{~kg}, p=0.001)$. The proportion of LBW neonate was $17.8 \%$ in the intervention group and $38.2 \%$ in the control group $(p<0.001)$. Multivariable logistic regression analysis showed that the risk of LBW in the control group was 2.43 more likely than in the intervention group (AOR $=2.43 ; 95 \% \mathrm{Cl}:(1.2,4.92)$.

\section{Conclusion}

Nutrition education and counseling delivered to pregnant women on the time of pregnancy could reduce maternal malnutrition and low birth weight. We can recommend that; the intervention is easy to implement in health facilities of Gedeo zone and would be implemented without delay to achieve sustainable development goals.

The trial was retrospectively registered in Pan African Clinical Trial Registry (www.pactr.org) database with unique identification number for the registry is PACTR202101757871954.

\section{Background}

Pregnancy is critical phase in a girl's life, and in this situation, women need aware of the healthy diet importance and information related to nutrition. Adequate nutritious food during pregnancy is important 
for the woman's health as well as the healthy growing fetus and economic productivity later in life (1).

Appropriate nutrition during pregnancy plays a fabulous role both for the mother and fetus because of the high nutrient and energy requirements. An adequate nutrient intake by the women before and during pregnancy can reduce the risk of medical problems of women's health and her infant $(2,3)$.

Stillbirth, miscarriage, low birth weight, death, delayed cognitive development, and sub-optimal productivity are all possible outcomes of malnutrition in pregnant women $(4,5)$.

In low- and middle-income countries of the world; many pregnant women have inadequate dietary intake of vegetables, meat, dairy products, and fruit (6). One factor that affects nutrient intake during pregnancy is insufficient knowledge of the pregnant women on diet (7).

Nutrition education and counseling is a good approach to improve the nutritional status of women and gestational weight gain during pregnancy (7-10). Nutrition education and counseling focus on enhancing intake of nutritious food during the third and fourth trimester of pregnancy significantly reduced the prevalence of low birth weight and increased maternal weight (11).

In Ethiopia, the extent of maternal and child death is high because of under-nutrition and micronutrient deficiencies. The Ethiopian Demographic Health Survey reported that a maternal mortality rate of 412 per 100,00 live birth and 67 child deaths per 1000 live births in 2016, and the prevalence of low birth weight (infant's weight less than $2.5 \mathrm{~kg}$ ) was $13.5 \%(12)$.

There is a high occurrence of insufficient dietary diversity practice among pregnant women in various parts of Ethiopia. In rural areas pregnant women had limited understanding on dietary diversity practices and they have positive attitude towards nutritional education.

In Ethiopia, $62 \%$ of pregnant women received at least one ANC visit for their most recent birth, and $66 \%$ of these women claimed to have received nutritional education and counseling, although the quality and quantity of this counseling was unknown (12).

Malnutrition among pregnant women and their children will remain a major concern in Ethiopia and other low- and middle-income countries until an adequate nutritional education and counseling program can be included into existing programs such as ANC (6). The effect of nutrition education given by the usual health service should be examined, and possible remedial action should have to be taken. Therefore, this study aimed to investigate the effect of nutrition education and counseling on the obstetric outcomes of pregnancy among pregnant mothers in Gedeo zone, southern Ethiopia.

\section{Methods}

\section{Study Design and Period}


Institutional based cluster randomized control trial was conducted from January to July 2019.

\section{Source and study population}

All pregnant mothers attending anti natal care service at public health facilities of Gedeo Zone were the source population and randomly selected pregnant mothers that followed ANC service at randomly selected public health facilities of Gedeo Zone were the study population.

\section{Inclusion and Exclusion Criteria}

All Pregnant mothers in the second trimester (4th \&5th month) of pregnancy attending ANC service at selected health institutions were included in this study and pregnant mothers $<18$ years and comorbidities with complications and special requirements were excluded from the study.

\section{Sample Size Determination}

The sample size for this study was calculated using online calculator for cluster randomized control trial with the following assumption. The standard normal deviate for $a=Z a=1.96$, Power $=80 \%$, number of clusters in each group 3 (advisable to limit the number of clusters), the average number of cluster size $\mathrm{m}$ = 42 (Obtained from health facilities Average ANC customer flow) and within-cluster correlation coefficient $(\rho), I C C=0.01$. Design effect $=1+(\rho(m-1))=1.41(13)$, Intervention group size $=N^{\prime} 1=101$, and Control group size $=\mathrm{N}^{\prime} 0=101$; Size of combined group Total, N=202. Adding 20\% nonresponse rate, finally 242 (121 in control and 121 in the intervention group) were enrolled in this study. Because of problems as described in Fig. 1, the actual data were collected from 115 pregnant women in the intervention group and 120 pregnant women in the control group. The CONSORT diagram of this the trial was prepared based on the Consolidated Standards of Reporting Trials (CONSORT) statement (Fig. 1).

The ethical letter was obtained from the Ethical Review Committee of Dilla University with unique number 007/19-01) to conduct the trial.

\section{Sampling Procedure}

From the total of 38 public health institutions in Gedeo zone, six institutions namely (Dilla hospital, Wonago hospital, Bulle hospital, Yirga chefe hospital, Cheleleketu health center, and Gedeb Hospital) were selected by a simple random sampling method. These institutions were equally and randomly assigned as an intervention group and control group using the SRS (lottery) method. Information about patient flow to the health institutions indicated that an average of 42 women for two weeks. The computed sample size was proportionally distributed to the selected health care institution based on the average number of women who visited ANC service. Pregnant women from each health institution were selected by simple random sampling technique based on their medical registration number.

\section{Data Collection Instruments and Procedures}

Using pre-designed structured questionnaires, data were collected by interview, anthropometric measurements, and hemoglobin level measurement. The questionnaires were composed of socio- 
demographic and economic factors, feeding practices, and adherence to iron-folic acid supplementation. The data collectors were six trained female Diploma Nurses and three BSc Nurses meant supervision should be accomplished by recruited supervisors. The training was given by a nutritionist.

Anthropometric Measurements: Measurements were taken by standardized and calibrated equipment. Height was measured barefoot on a cleaned surface, in light clothing and avoid any pins and braids from the hair that could affect the measurement and recorded to the nearest $0.1 \mathrm{~cm}$ and positioning the subject at the Frankfurt plane using a stadiometer Seca (Germany). Weight was measured with light clothing in a closed room by a female data collectors and recorded to the nearest $0.1 \mathrm{~kg}$ using UNICEF Seca digital weighing scale (Germany) (Gibson, 2005) (14). Mid-upper arm circumference (MUAC) was taken from the left-arm using non-stretchable flexible tape.

Dietary Diversity Score (DDS): was computed for each pregnant woman during the previous 24 hours. The dietary questionnaires contained ten different food groups based on their nutrients: those include grains (white roots, tubers, and plantains), pulses (beans, peas, and lentils), nuts and seeds, dairy, meat (poultry and fish), eggs, dark green leafy vegetables, vitamin A-rich fruits and vegetables, vegetables, and fruits. To categorize women's dietary diversity, as women who eat five or above and less than five different food items have a high and low dietary diversity score respectively (15).

Nutrition Education and Counseling: It was given by an experienced health education and nutrition experts and delivered to the intervention group four times based on the time frame for consecutive four months. The content of NEC is modified from the new Blended Training Module on Nutritional Counseling for Pregnant Women in Ethiopia $(10,16)$. Each education sessions were for one hour, and the first section was before an initial interview to obtain baseline data. The nutrition educations were delivered in a counseling format and emphasis on promoting behavioral change. The content of the section included the nutritional value of food, the essence of balanced diet, cooking practices for optimum retention of nutrients, and creating awareness about food taboos relating to pregnancy and infant feeding, health, and hygiene practices, disease control, food frequency demonstration provided on cooking vegetables, highly nutritious local dish that can be made with affordable, readily available ingredients. The method of education delivered consists of lectures, questions, and answers, role play, drama, brochures, leaflets photographs were used to deliver key information; finally, specific counseling was given to the intervention groups individually during their ANC follow-up.

Women in the control group received nutrition counseling (routine health service) given by health extension workers based on the general usual service.

\section{Operational Definitions}

Gestational Weight Gain: Is defined as any additional weight the woman gains during pregnancy from the point of conception to the end of the pregnancy.

Low Birth Weight: weight of less than $2500 \mathrm{~g}$ at birth. 
Intervention Group: Those who receive intensive NEC by nutritionist expert, According to the new blended Training Module on Nutritional Counseling for Pregnant Women in Ethiopia (10).

Control Group: Those who receive routine services only.

\section{Data Quality Control}

The questionnaire was organized in English and translated into the local language Gedeofa and translated back to English to increase respondents understanding on the question. A pretest of the questionnaire was done on $5 \%$ of the sample size at Chuchu health center before the actual data collection. Height and weight measurements were taken twice for each mother. All anthropometric measurements were measured by trained diploma nurses and relative technical error of measurement was calculated to check intra-observer variability. The weight scale would be calibrated to zero levels with no object on it and placed on the level surface before the measurement was performed. The scale of measurements was checked continuously for their reliability. Supervision by the principal investigator was accomplished to check the completeness of the collected data and logical consistency. Therefore, everything would be corrected on the spot.

\section{Data Processing and Analysis}

Data was coded and entered by use of EPI-DATA 3.2 and analyzed in Stata-software. Descriptive summaries like frequency, proportions, cross tabs, and graphical presentation. Kolmogorov Smirnov and Leven tests were used to assess the normality and homogeneity of the data. Independent t-test was used to analyze the group difference for continuous variable and chi-square test for categorical variables. The post intervention values between two groups were compared using ANCOVA by adjusting to baseline data. Logistic regression analysis was used to examine the effects of the intervention on low birth weight by adjusting other confounding factors. Here the non-statistical significance result of Hosmer Lemeshow test showed that the multivariable logistic regression model fits the data well, and the association was checked by P-value $<0.05, \mathrm{AOR}$, and $95 \% \mathrm{Cl}$ were considered as associated factors.

\section{Results}

\section{Socio-Demographic Characteristics of Pregnant Women}

Among 242 pregnant women who enrolled in this study, 135 (intervention group $=115$, control group $=$ 120) were included in the analysis. The mean age of pregnant women in the intervention group was 25.9 $(S D \pm 4.9)$ and 26.01 (SD \pm 5.2$)$; and the most of the pregnant women lies between in the age of 20 to 29 years in both groups. Regarding the status of education $76.1 \%$ in the intervention group and $78.2 \%$ in the control group of the study, participants were attended primary education and above. At the baseline of this study, the mean body weight of the women was $56.69 \mathrm{~kg}(\mathrm{SD} \pm 6.9)$ in the intervention group and $55.95 \mathrm{~kg}(\mathrm{SD} \pm 7.6)$ in the control group. 
Generally, at baseline, the two groups were no statistically significant difference in all socio-demographic characteristics of the participants $(P>0.05)$ (Table 1$)$. 
Table 1

Baseline characteristics of women in control and intervention group, Gedeo Zone.

\begin{tabular}{|c|c|c|c|}
\hline Variable & $\begin{array}{l}\text { Intervention Group } \\
(=115) \mathrm{n}(\%)\end{array}$ & $\begin{array}{l}\text { Control Group } \\
(=120) n(\%)\end{array}$ & p-value \\
\hline Age group 15-19 & $9(7.83)$ & $8(6.6)$ & 0.09 \\
\hline $20-24$ & $52(45.2)$ & $37(30.6)$ & \\
\hline $25-29$ & $31(26.9)$ & $34(28.1)$ & \\
\hline $30-34$ & $17(7.8)$ & $28(23.1)$ & \\
\hline $35+$ & $6(5.2)$ & 13(10.7) & \\
\hline Religion Orthodox & $54(45.2)$ & $56(46.2)$ & 0.48 \\
\hline Muslim & $40(33.9)$ & $32(26.7)$ & \\
\hline Protestant & 12(10.6) & $21(17.2)$ & \\
\hline Other & $9(6.8)$ & $11(9.5)$ & \\
\hline Women Educational status & $24(20.67)$ & $24(20.67)$ & 0.16 \\
\hline No education & $41(35.7)$ & $41(35.7)$ & \\
\hline Primary & $32(27.8)$ & $32(27.8)$ & \\
\hline Secondary & $18(15.7)$ & 18(15.7) & \\
\hline \multicolumn{4}{|l|}{ Higher and above } \\
\hline Occupation Of Women & $43(37.4)$ & $48(40.2)$ & 0.30 \\
\hline Housewife & $26(22.6)$ & $21(17.5)$ & \\
\hline Employee & $39(33.7)$ & $49(40.8)$ & \\
\hline Merchant & $7(6.3)$ & $2(1.7)$ & \\
\hline \multicolumn{4}{|l|}{ Other } \\
\hline Marital status, Married & $99(90.8)$ & 101(84.2 & 0.33 \\
\hline Unmarried/Divorced & $16(9.2)$ & $19(15.8)$ & \\
\hline
\end{tabular}




\begin{tabular}{|llll|}
\hline Variable & $\begin{array}{l}\text { Intervention Group } \\
(=115) \mathbf{n}(\%)\end{array}$ & $\begin{array}{l}\text { Control Group } \\
(=120) \mathbf{n}(\%)\end{array}$ & p-value \\
\hline Husband education & $16(13.9)$ & $20(16.5)$ & 0.10 \\
No education & $30(26.1)$ & $39(32.5)$ & \\
Primary education & $47(40.9)$ & $51(42.47)$ & \\
Secondary & $22(19.3)$ & $10(8.4)$ & \\
Higher and above & & & \\
\hline Monthly income in ETB & $28(23.3)$ & $28(23.33)$ & 0.16 \\
\hline$<999 E T B$ & $44(36.7)$ & $27(22.5)$ & \\
1000-1999 & $43(35.8)$ & $65(54.17)$ & \\
\hline$>=2000$ & & & \\
\hline Family size $<5$ & $97(80.8)$ & $101(84.17)$ & 0.88 \\
\hline$>=5$ & $18(19.2)$ & $19(15.83)$ & \\
\hline Gravidity Prima & $37(32.2)$ & $24(19.7)$ & 0.04 \\
multi-gravidity & $78(67.8)$ & $96(79.3)$ & \\
\hline Weight & $(56.69 \pm 6.98)$ & $(55.95 \pm 7.6)$ & 0.83 \\
\hline DD score & $(11.93 \pm 1.6)$ & $(11.58 \pm 1.4)$ & 0.09 \\
\hline MUAC & $(23.67 \pm 2.5)$ & $(23.08 \pm 1.76)$ & 0.06 \\
\hline Continuous values are expressed as mean \pm standard deviation & \\
\hline
\end{tabular}

\section{Nutritional Status of Pregnant Women}

At the end line of the study the mean scores of weight, MUAC, and dietary diversity scores $(P<0.01)$ were significantly higher in the intervention group compared to the control group. The nutrition education and counseling intervention had a significant effect on maternal weight gain, MUAC, and dietary diversity practice of pregnant women. Weight gain is the difference in weight before labor and weight as on the first ANC visit; gestational weight gain in the intervention arm was significant higher than those in the control group $(65.03 \mathrm{~kg}$ vs. $56.69 \mathrm{~kg}, \mathrm{p}=0.001)$. Women enrolled in the intervention had a mean weight gain of $10.08 \mathrm{~kg}$ : however, those in the control group had a mean weight gain of $2.22 \mathrm{~kg}$ (Table 2). 
Table 2

Differences between baseline and end-line measurements of weight, MUAC, and DDS and adjusted group differences $(95 \% \mathrm{Cl})$ of the posttest.

\begin{tabular}{|lllll|}
\hline Variable & Baseline & End line & Adjusted mean difference to controls & p-value \\
\hline Women's Weight & $(54.58 \pm 5.1)$ & $(56.8 \pm 7.6)$ & $10.08(9.55,10.60)$ & 0.001 \\
Control & $(56.69 \pm 6.3)$ & $(65.03 \pm 7.2)$ & & \\
Intervention & & & & 0.029 \\
\hline DDS Control & $(11.47 \pm 1.8)$ & $(11.8 \pm 1.6)$ & $0.15(0.16,0.45$ & 0.00 \\
Intervention & $(11.9 \pm 1.5)$ & $(12.5 \pm 1.4)$ & & \\
\hline MUAC Control & $(23.04 \pm 1.8)$ & $(23.8 \pm 1.6)$ & $1.27(1.12,1.42)$ & \\
Intervention & $(23.59 \pm 2.5)$ & $(24.35 \pm 1.4)$ & & \\
\hline $\begin{array}{l}\text { Cl; confidence interval, ANCOVA; mean group differences adjusted for baseline variables, economic } \\
\text { status, educational level, gravidity... }\end{array}$
\end{tabular}

Based on this finding the result persists after adjusting the potential confounder variables; and it was concluded that nutrition education and counseling intervention in the study was efficient in terms of improving the dietary practice and better body weight gain of pregnant women.

\section{Comparison of Birth Weight between Intervention and Control Groups}

At the end line of this study the mean birth weight in the intervention group was $0.19 \mathrm{~kg}$ greater than that in the control group ( $3.07 \mathrm{vs}$. $2.88 \mathrm{~kg}, \mathrm{p}=0.001$ ). The control group had a larger proportion of newborns with low birth weight than the intervention group. The proportion of LBW babies was $17.5 \%$ in the intervention group and $35.2 \%$ in the control group $(p<0.001)$ (Table 3 ).

Table: 3 Comparison of birth weight between intervention and control groups.

\begin{tabular}{|l|l|l|l|}
\hline & $\begin{array}{l}\text { Intervention group } \\
\mathrm{n}=103\end{array}$ & $\begin{array}{l}\text { Control group } \\
\mathrm{n}=108\end{array}$ & p-value \\
\hline Birth weight (kg) & $(3.01 \pm 0.46)$ & $(2.88 \pm 0.4)$ & 0.001 \\
\hline LBW- no. (\%) & $18(17.5)$ & $38(35.2)$ & \\
NBW no.(\%) & $85(82.5)$ & $70(64.8)$ & 0.001 \\
\hline
\end{tabular}

a. Independent T-test.

b. LBW, low birth weight $(<2.5 \mathrm{Kg})$; NBW, Normal Birth Weight $(\geq 2.5 \mathrm{~kg})$

c. Chi-square test; Missing from intervention group, $\mathrm{n}=12$, and from control group, $\mathrm{n}=$ 


\section{Effect of Nutrition Education Intervention on Birth Weight}

After controlling other possible confounder variables (gestational age, maternal weight, family size, source of drinking water and latrine utilization), the multivariable logistic regression analysis showed that the risk of LBW in the control group was 2.43 more likely than in the intervention group [(AOR=2.43; $95 \%$ $\mathrm{Cl}:(1.2,4.92)]$. In this analysis, variables that have a statistically significant association with low birth weight were women in the intervention group, no educational level and secondary educational level, and household monthly income $<2000$ ETB. The risk of LBW babies was 2.14 times higher in babies who were born in family monthly income $<2000$ ETB than with family income $\geq 2000 E T B$ [(AOR=2.14; $95 \%$ Cl: (1.14.26)]. The mothers who had no formal educational level had 2.55 times higher chance of having LBW babies than mothers who had secondary and above educational level $[A O R=2.55 ; 95 \% \mathrm{Cl}:(1.06,6.14)]$ (Table 4).

Table 4 Bi-variable and multivariable logistic regression analyses of low birth weight in public health facilities of Gedeo zone, 2019. 


\begin{tabular}{|c|c|c|c|c|}
\hline Risk Factors & $\begin{array}{ll}\text { LBW no. } & \text { no. } \\
(\%) & \\
\end{array}$ & $\begin{array}{ll}\text { NBW no. } & \text { no. } \\
(\%) & \end{array}$ & COR(95\%CI) & AOR(95\%CI) \\
\hline $\begin{array}{l}\text { Group } \\
\quad \text { Control } \\
\text { Intervention }\end{array}$ & $\begin{array}{l}38(35.2) \\
18(17.5)\end{array}$ & $\begin{array}{l}70(64.5) \\
85(82.5)\end{array}$ & $\begin{array}{l}2.56(1.35- \\
4.87)^{*} \\
\operatorname{Ref}\end{array}$ & $\begin{array}{l}\text { 2.43(1.19-4.93)* } \\
\operatorname{Ref}\end{array}$ \\
\hline $\begin{array}{l}\text { Women's Education } \\
\text { No education } \\
\text { Primary } \\
\text { Secondary \&above }\end{array}$ & $\begin{array}{l}36(19.1) \\
17(19.4) \\
12(34.6)\end{array}$ & $\begin{array}{l}38(80.9) \\
49(80.6) \\
68(65.4)\end{array}$ & $\begin{array}{l}2.24(0.97-5.13) \\
3.36(1.09- \\
5.08)^{*} \\
\text { Ref }\end{array}$ & $\begin{array}{l}2.55(1.06-6.14)^{*} \\
2.04(1.02-4.56)^{*} \\
\operatorname{Ref}\end{array}$ \\
\hline $\begin{array}{l}\text { Family Monthly Income } \\
\quad<2000 \\
\geq 2000\end{array}$ & $\begin{array}{l}33(22.8) \\
23(34.3)\end{array}$ & $\begin{array}{l}111(77.2) \\
44(65.7)\end{array}$ & $\begin{array}{l}0.57(0.3-0.97) * \\
\text { Ref }\end{array}$ & $\begin{array}{l}2.14(1.1-4.26) * \\
\operatorname{Ref}\end{array}$ \\
\hline $\begin{array}{l}\text { Mother's Occupation } \\
\text { Housewife } \\
\text { Employee } \\
\text { Other } \\
\end{array}$ & $\begin{array}{l}27(32.1) \\
10(25.0) \\
19(21.5) \\
\end{array}$ & $\begin{array}{l}57(69.9) \\
30(75.0) \\
68(78.5) \\
\end{array}$ & $\begin{array}{l}1.4(0.27-6.4) \\
0.98(0.2-5.3) \\
\text { Ref }\end{array}$ & $\begin{array}{l}1.4(0.3-3.4) \\
0.78(0.2-2.6) \\
\operatorname{Ref}\end{array}$ \\
\hline $\begin{array}{l}\text { Mother's } \text { End line } \\
\text { MUAC } \\
\quad<23 \\
\quad \geq 23\end{array}$ & $\begin{array}{l}33(27.7) \\
22(24.3)\end{array}$ & $\begin{array}{l}87(72.5) \\
68(75.7)\end{array}$ & $\begin{array}{l}1.17(0.93-3.21) \\
\text { Ref }\end{array}$ & $\begin{array}{l}0.7(0.59-0.96) \\
\operatorname{Ref}\end{array}$ \\
\hline $\begin{array}{l}\text { Women's End line DDS } \\
\text { Practice } \\
\text { Practice }\end{array}$ & $\begin{array}{l}49(29.7) \\
7(15.2)\end{array}$ & $\begin{array}{l}116(70.3) \\
39(84.8)\end{array}$ & $\begin{array}{l}0.43(0.18-1.02) \\
\text { Ref }\end{array}$ & $\begin{array}{l}0.46(0.19-1.09) \\
\text { Ref }\end{array}$ \\
\hline
\end{tabular}

*p-value $<0.05$

\section{Discussion}

This study verified the effect of nutrition education and counseling intervention to improve dietary behavior and the effect on weight gain during pregnancy and subsequent birth weight.

To enhance the nutritional status of pregnant women, the World Health Organization (WHO) promotes nutrition education and counseling (17). Therefore, this study tried to assess the effects of nutrition counseling on dietary practices and nutritional status of pregnant women. The result shows that significant improvements in good dietary practice. The result of this finding is similar to those studies done in Pakistan and Iran $(7,11)$. 
In this study the intervention group increased on an average weight gain from the baseline to the ninth month of pregnancy was $10.08 \mathrm{~kg}$ and $2.22 \mathrm{~kg}$ for the control group, which was higher than the weight gain reported by studies done in India and Bangladesh $(9,18)$. The findings of this study confirmed the effectiveness of nutrition education and counseling in improving gestational weight gain and birth weight. The success of this intervention may be due to the study setting; i.e. institutional based intervention method used and others were community based intervention.

The findings of this study also agreed with other studies done in Pakistan, Kenya and West Gojjam zone, Ethiopia $(11,19,20)$, where they showed that due to the helpful effect of nutrition education and counseling intervention; women could improve dietary practice and gestational weight gain. Women in the intervention group were more likely to have proper dietary practices than the control groups. The poor counseling practice of the health workers could be a possible explanation for the inappropriate dietary practices of pregnant women in the control group.

In Ethiopia, low birth weight is associated with maternal malnutrition, lack of antenatal care visits, lack of nutrition counseling, birth interval less than two years, inadequate food intake during pregnancy, and a lack of education $(21,22)$. In this study, the mean birth weight in the intervention group was $0.19 \mathrm{~kg}$ larger than the mean birth weight of the control group. The finding of this study agreed with other studies done in Bangladesh and west Gojjam Ethiopia $(9,19)$, where they suggested that low birth weight in the control group was higher than in the intervention group. This difference might be due to the effect of nutrition educations given for the intervention group. The 2016 EDHS also revealed a 13\% prevalence of LBW which is lower than this study result (12). In this study the control group had a higher rate of low birth weight than the intervention group.

After fitting the multivariable logistic regression model, the results also revealed that low birth weight infants were lower in the intervention group compared with the control group. This study found that the risk of LBW babies was $39.6 \%$ higher in babies who were born from household monthly income $\leq$ 2000ETB than household monthly income $>2000$ ETB. Our research finding is consistent with previous studies done by different scholars $(9,21)$. However, this study result is not consistent with the study done in India (18), and found that normal birth weight is weakly associated with maternal weight gain and which was not found to be statistically different between the two groups at the end line of the study.

Having enough amount of balanced diet plays a vigorous role in refining the pregnant women's weight and birth weight. In this study area, foods items found at home may not be diversified to fulfill the balanced diet of all pregnant women. While nutrition expert and health extension workers advise for pregnant women to take foods present at home by adding more nutritious food compared with women's usual diet.

The strength of this study was being an effective intervention trial by applying a client-based approach during mothers ANC follow-up time, and its applicability to in all maternity health care institution, and to community-based programs. The rate of loss to follow up is also a limitation of this study and supplementary qualitative information was not taken were the limitation for this study. 


\section{Conclusion}

According to these findings, it was concluded that nutrition education and counseling is a possible approach to improve gestation weight gain and a strong reduction in the rate of low birth weight. The intervention is simple to implement in all maternal health care institutions and could be accomplished during ANC follow-up through health education and nutrition expert using a client-centered approach.

We can recommend that the intervention is easy to implement in health care institutions of Gedeo zone and would be implemented without delay to achieve sustainable development goals.

\section{Abbreviations}

ANC, Anti Natal Care; DDS, Dietary diversity score; GWG, Gestational weight gain; LBW, low birth weight; BBW, normal birth weight; MUAC, Mid-upper arm circumference; NEC, Nutrition education and counseling; SDG, Sustainable development goal

\section{Declarations}

\section{Ethics approval and consent to participate}

The study was reviewed and approved by the Institutional Review Board (IRB) of Dilla University College of Medicine and Health Science. The study purpose, procedures, possible risks, and benefits were explained to participants in local languages. Informed written consent was obtained and signed. Confidentiality of information collected from each study participant didn't disclose. They were informed that they have full rights to withdraw from the study at any time if they face any difficulties. The trial was retrospectively registered in Pan African Clinical Trial Registry (www.pactr.org) database with unique identification number for the registry is PACTR202101757871954.

Consent to Publication: Not applicable

Availability of Data Materials: Datasets used and/or analyzed during the current study are available from the corresponding author on reasonable request.

Competing Interests: The authors declare that they have no competing interests.

Funding: The study was funded by Dilla University, Ethiopia. The funder had no role in the study design, data collection, analysis, and interpretation of data.

\section{Authors' Contributions}

GS: conceived and designed the study, conducted statistical analysis and result interpretation, prepared manuscript. AT: conceived and designed the study, conducted the statistical analysis and result interpretation. The author read and approved the manuscript. 


\section{Acknowledgement}

First and foremost, we would like to express our deepest gratitude to Dilla University for allowing us to do the research project. Secondly, we express our heartfelt gratitude to Colleague Instructors of Public Health for their unreserved, all-rounded, supported, and enriching comments. We would also like to extend our appreciation to the data collectors and participants in the study.

\section{Authors' Information}

Department of Public Health, College of Medicine and Health Science, Dilla University, P.O. Box 419, Dilla, Ethiopia. Department of Human Nutrition, College of Medicine and Health Science, Dilla University, P.O. Box 419, Dilla, Ethiopia.

\section{References}

1. Bain LE, Awah PK, Geraldine N, Kindong NP, Siga Y, Bernard N, et al. Malnutrition in Sub-Saharan Africa: burden, causes and prospects. Pan African Medical Journal. 2013;15(1).

2. Desyibelew HD, Dadi AF. Burden and determinants of malnutrition among pregnant women in Africa: A systematic review and meta-analysis. PloS one. 2019;14(9):e0221712.

3. Zerfu TA, Umeta M, Baye K. Dietary habits, food taboos, and perceptions towards weight gain during pregnancy in Arsi, rural central Ethiopia: a qualitative cross-sectional study. Journal of Health, Population and Nutrition. 2016;35(1):1-7.

4. Veena SR, Gale CR, Krishnaveni GV, Kehoe SH, Srinivasan K, Fall CH. Association between maternal nutritional status in pregnancy and offspring cognitive function during childhood and adolescence; a systematic review. BMC Pregnancy Childbirth. 2016;16:220.

5. Wilkinson SA, Tolcher D. Nutrition and maternal health: what women want and can we provide it? Nutrition \& Dietetics. 2010;67(1):18-25.

6. WHO Guidelines Approved by the Guidelines Review Committee. WHO Recommendations on Antenatal Care for a Positive Pregnancy Experience. Geneva: World Health Organization

Copyright @ World Health Organization 2016.; 2016.

7. Fallah F, Pourabbas A, Delpisheh A, Veisani Y, Shadnoush M. Effects of nutrition education on levels of nutritional awareness of pregnant women in Western Iran. International journal of endocrinology and metabolism. 2013;11(3):175.

8. Hidru HD, Berwo Mengesha M, Hailesilassie Y, Tekulu Welay F. Burden and Determinant of Inadequate Dietary Diversity among Pregnant Women in Ethiopia: A Systematic Review and MetaAnalysis. Journal of Nutrition and Metabolism. 2020;2020. 
9. Jahan K, Roy S, Mihrshahi S, Sultana N, Khatoon S, Roy H, et al. Short-term nutrition education reduces low birthweight and improves pregnancy outcomes among urban poor women in Bangladesh. Food and nutrition bulletin. 2014;35(4):414-21.

10. Omer AM, Haile D, Shikur B, Macarayan ER, Hagos S. Effectiveness of a nutrition education and counselling training package on antenatal care: a cluster randomized controlled trial in Addis Ababa. Health Policy and Planning. 2020;35(Supplement_1):i65-i75.

11. Kaleem R, Adnan M, Nasir M, Rahat T. Effects of antenatal nutrition counselling on dietary practices and nutritional status of pregnant women: A quasi-experimental hospital based study. Pakistan Journal of Medical Sciences. 2020;36(4):632.

12. Csa I. Central statistical agency (CSA)[Ethiopia] and ICF. Ethiopia demographic and health survey, Addis Ababa, Ethiopia and Calverton, Maryland, USA. 2016.

13. Kedir $\mathrm{H}$, Berhane $\mathrm{Y}$, Worku A. Magnitude and determinants of malnutrition among pregnant women in eastern E thiopia: evidence from rural, community-based setting. Maternal \& child nutrition. 2016;12(1):51-63.

14. Gibson RS. Principles of nutritional assessment: Oxford university press, USA; 2005.

15. FAO F. Minimum dietary diversity for women: a guide for measurement. Rome: FAO. 2016;82.

16. Ethiopia. FMoH. Blended and Integrated Nutrition Learning Module (BINLM), 2016a. Federal Ministry of Health Ethiopia. 2016(Federal Ministry of Health Ethiopia. 2016b).

17. de Masi S, Bucagu M, Tunçalp Ö, Peña-Rosas JP, Lawrie T, Oladapo OT, et al. Integrated personcentered health care for all women during pregnancy: implementing World Health Organization recommendations on antenatal care for a positive pregnancy experience. Global Health: Science and Practice. 2017;5(2):197-201.

18. Daniel S, Pu G, Gnanaraj S, Sharmine E. Effect of nutrition education among pregnant women with low body mass index: a community based intervention. Int $\mathrm{J}$ Community Med Public Health. 2016;3(11):3135-9.

19. Demilew YM, Alene GD, Belachew T. Effects of guided counseling during pregnancy on birth weight of newborns in West Gojjam Zone, Ethiopia: a cluster-randomized controlled trial. BMC pediatrics. 2020;20(1):1-12.

20. Nyamasege C, Kimani-Murage E, Wanjohi M, Kaindi DW, Ma E, Fukushige M, et al. Determinants of low birth weight in the context of maternal nutrition education in urban informal settlements, Kenya. Journal of developmental origins of health and disease. 2019;10(2):237. 
21. Siyoum M, Melese T. Factors associated with low birth weight among babies born at Hawassa University Comprehensive Specialized Hospital, Hawassa, Ethiopia. Italian journal of pediatrics. 2019;45(1):1-7.

22. Talie A, Taddele M, Alemayehu M. Magnitude of low birth weight and associated factors among newborns delivered in Dangla primary hospital, Amhara regional state, Northwest Ethiopia, 2017. Journal of Pregnancy. 2019;2019.

\section{Figures}




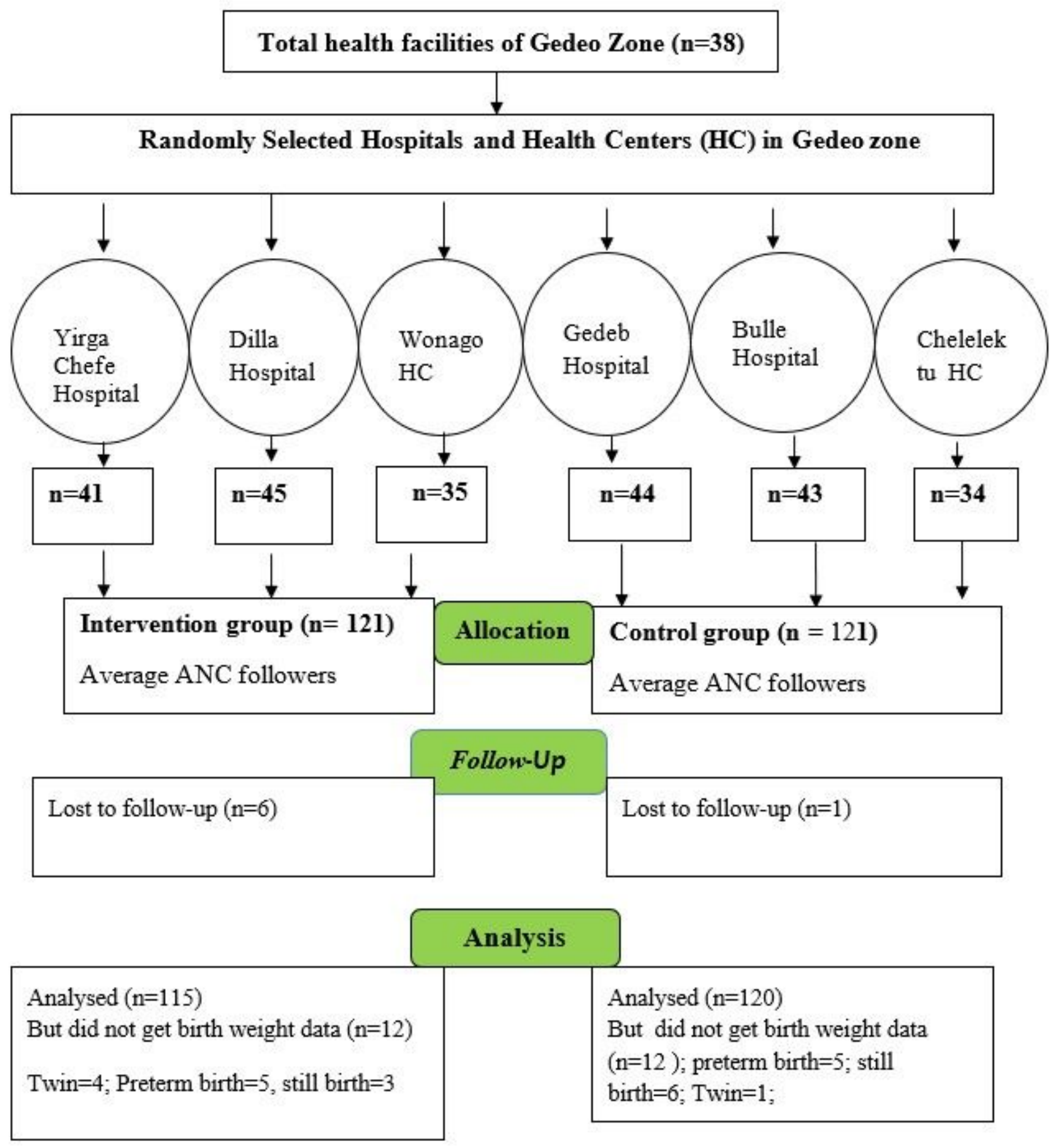

Figure 1

CONSORT flow chart shows the flow of participants through the trial based on the criteria recommended by the CONSORT guideline. 